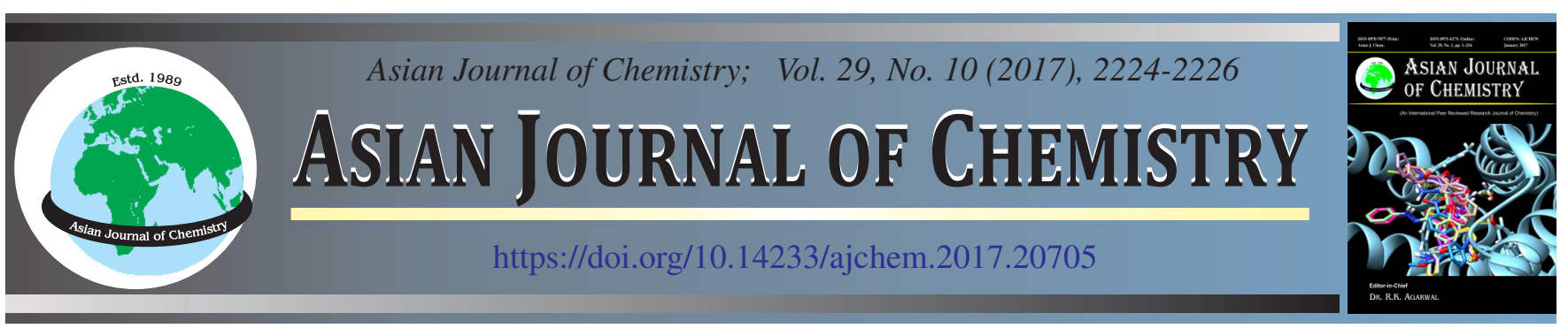

\title{
Molecular and Electronic Structure of Some Symmetrically meso-Substituted Hg(II)-Porphyrin Complexes
}

Hafiz Aji Aziz, Grisani Ambar Santoso, Fadjar Mulya and Harno Dwi Pranowo*

Department of Chemistry, Faculty of Mathematic and Natural Sciences, Universitas Gadjah Mada, Yogyakarta 55281, Indonesia

*Corresponding author: Tel: +62 812 2716524, E-mail: harnodp@ugm.ac.id

A theoretical study on the effect of substituent group on the molecular and electronic structure of some meso-substituted Hg(II)-porphyrin complexes using DFT-B3LYP/LanL2DZ method had been performed. The calculation result showed that the molecular structure of the complexes and density of states abundance of virtual orbital is independent of the substituent group effect. The band gap energy and density of states abundance of occupied orbital however is decrease for the complexes with electron donating group.

Keywords: Mercury(II), Porphyrin, Hg(II)-porphyrin, Molecular structure, Semiconductor.

\section{INTRODUCTION}

Porphyrin and its derivatives are known for their role in organism as part of enzymes, vitamins and even red blood cells. On the other side, porphyrin and its derivatives were also known for their unique photoreactivity [1,2] and narrow band gap for semiconductor applications. Some of porphyrin derivatives in the form of metalloporphyrin complexes has been proven to have the properties of a semiconductor materials such as $\mathrm{Pt}(\mathrm{II})$-porphyrin, $\mathrm{Fe}(\mathrm{II})$-porphyrin, $\mathrm{Mg}$ (II)-porphyrin and zinc group-porphyrin complexes [3-8].

Metalloporphyrin complexes performance as semiconducting materials is determined by the central ion of the complexes and the functional group that is substituted on the porphyrin ring $[5,9]$. We have previously discussed how those factors help us to design a better metalloporphyrin semiconductor by looking into the electronic structures of some meso-substituted $\mathrm{M}(\mathrm{II})$-porphyrin ( $\mathrm{M}=\mathrm{Pt}, \mathrm{Cd}, \mathrm{Hg}$ ) [9]. In this paper we will further discussed the both electronic and molecular structure and properties of some meso-substituted $\mathrm{Hg}$ (II)-porphyrin.

\section{EXPERIMENTAL}

meso-Substituted $\mathrm{Hg}(\mathrm{II})$-porphyrin complexes molecular model were used. There are 10 complexes coded as HgP-R where $-\mathrm{R}$ are $-\mathrm{CH}_{3},-\mathrm{CHO},-\mathrm{COOH},-\mathrm{F},-\mathrm{I},-\mathrm{NH}_{2},-\mathrm{NO}_{2},-\mathrm{OH}$ and $\mathrm{Ph}$ (phenyl group) and non-substituted $\mathrm{Hg}$ (II)-porphyrin complex $(\mathrm{HgP}-\mathrm{H})$ were used as standard.

All calculation were performed on High Performance Computer on Direktorat Sistem dan Sumber Daya Informasi,
Universitas Gadjah Mada (DSSDI UGM) and AustrianIndonesian Centre (AIC) for Computational Chemistry using Gaussian 09 package software [10] and GaussSum 2.2.5 [11].

Geometry optimization: Geometry optimization was performed using density functional theory (DFT) calculation using Becke's 3 parameters with Lee, Yang and Parr exchangecorrelation function (B3LYP) [12-15] and Hay and Wadt LanL2DZ basis set on Gaussian 09 package software.

Density of states: Density of states calculation were performed using Landau algorithm on GaussSum 2.2.5 software $(\mathrm{E}=-10-0 \mathrm{eV})$.

\section{RESULTS AND DISCUSSION}

Calculation methods validation: Validation of calculation method that were performed need to be done in order to justifies the accuracy of the method. The validity of the method were tested by comparing the calculation result with experimental result. In this research we compared the molecular structure of meso-(tetra-p-cyanophenyl)porphyrinatomercury(II) (Hg-TPPC) core from single crystal XRD measurement [16] with the DFT/B3LYP/LanL2DZ calculation result.

By comparing both result we can see that the average relative deviation of the calculation result is less than $2.5 \%$ which mean that the DFT/B3LYP/LandL2DZ calculation is valid method to calculate the molecular structure of HgP-R.

Molecular structure of HgP-R: Porphyrin is an aromatic molecule, therefore both its molecular and dianionic structure are planar with $\mathrm{D}_{2 \mathrm{~h}}$ and $\mathrm{D}_{4 \mathrm{~h}}$ symmetry. Substituted metallo- 
TABLE-1

STRUCTURAL PARAMETERS OF HgP-R CORE

\begin{tabular}{|c|c|c|c|c|c|c|c|c|c|c|}
\hline \multirow{2}{*}{$\mathrm{R}$} & \multicolumn{4}{|c|}{ Bond length $(\AA)$} & \multicolumn{6}{|c|}{ Bond angle $\left({ }^{\circ}\right)$} \\
\hline & $\mathrm{Hg}-\mathrm{N}_{1}$ & $\mathrm{Hg}-\mathrm{N}_{2}$ & $\mathrm{Hg}-\mathrm{N}_{3}$ & $\mathrm{Hg}-\mathrm{N}_{4}$ & $\mathrm{~N}_{1}-\mathrm{Hg}-\mathrm{N}_{2}$ & $\mathrm{~N}_{1}-\mathrm{Hg}-\mathrm{N}_{3}$ & $\mathrm{~N}_{1}-\mathrm{Hg}-\mathrm{N}_{4}$ & $\mathrm{~N}_{2}-\mathrm{Hg}-\mathrm{N}_{3}$ & $\mathrm{~N}_{2}-\mathrm{Hg}-\mathrm{N}_{4}$ & $\mathrm{~N}_{3}-\mathrm{Hg}-\mathrm{N}_{4}$ \\
\hline $\mathrm{CH}_{3}$ & 2.239 & 2.239 & 2.239 & 2.239 & 86.790 & 152.607 & 86.686 & 86.889 & 152.643 & 86.796 \\
\hline $\mathrm{CHO}$ & 2.241 & 2.241 & 2.241 & 2.241 & 87.213 & 154.536 & 87.213 & 87.205 & 154.503 & 87.219 \\
\hline $\mathrm{COOH}$ & 2.234 & 2.234 & 2.234 & 2.234 & 87.239 & 154.673 & 87.253 & 87.253 & 154.681 & 87.239 \\
\hline F & 2.250 & 2.250 & 2.250 & 2.250 & 86.042 & 149.542 & 86.041 & 86.049 & 149.537 & 86.040 \\
\hline $\mathrm{H}$ & 2.241 & 2.241 & 2.241 & 2.241 & 86.789 & 152.612 & 86.775 & 86.807 & 152.605 & 86.774 \\
\hline I & 2.238 & 2.239 & 2.239 & 2.239 & 87.098 & 153.839 & 87.047 & 87.021 & 153.760 & 87.056 \\
\hline $\mathrm{NH}_{2}$ & 2.246 & 2.246 & 2.247 & 2.246 & 86.624 & 151.695 & 86.565 & 86.569 & 151.848 & 86.606 \\
\hline $\mathrm{NO}_{2}$ & 2.248 & 2.245 & 2.245 & 2.246 & 86.517 & 151.621 & 86.548 & 86.713 & 151.886 & 86.548 \\
\hline $\mathrm{OH}$ & 2.241 & 2.251 & 2.245 & 2.248 & 86.477 & 149.625 & 85.999 & 86.710 & 151.791 & 86.175 \\
\hline $\mathrm{Ph}$ & 2.242 & 2.224 & 2.242 & 2.224 & 87.429 & 151.543 & 87.447 & 87.442 & 159.058 & 87.491 \\
\hline
\end{tabular}

porphyrin complexes structure however is dependent on the central ion and their substituent group. It had been showed that substituted $\mathrm{Ni}(\mathrm{II})$-porphyrin complexes exhibit a negatively curved structure (hyperbolic) with nearly perfect $\mathrm{D}_{2 \mathrm{~d}}$ symmetry with the amount of curvature that varies according to the substituent group [8]. $\mathrm{Hg}(\mathrm{II})$-porphyrin complexes however exhibit a structure with positive curvature (elliptic) with nearly perfect $\mathrm{C}_{4 \mathrm{v}}$ symmetry.

Unlike $\mathrm{Ni}$ (II)-porphyrin, HgP-R curvature is independent of the substituent group. This effect is due the large size of $\mathrm{Hg}(\mathrm{II})$ ion, making the steric effect of the central ion become the dominant factor in determining the molecular structure over the substituent effect, therefore making the core structure of all the complexes nearly identical (Table-1).

Electronic structure: In order to discuss the effect of the different substituent group to the electronic structure of HgP-R, ones first have to realize that the electronic structure is a function of electronic density which mean that the substituent effect on the electronic structure will be more conclusive than to the molecular structure.

Band gap and frontier orbitals energy: Band gap energy is a parameter that determine the minimal energy requirement an electron needed to be excited from occupied orbitals to the virtual unoccupied orbitals. In molecular semiconductor, the band gap can be approximated by Kohn-Sham band gap that defined by the energy difference between the frontier orbitals (HOMO and LUMO).

The energy of the frontier orbitals and band gap of $\mathrm{HgP}-$ Rs are given in Table-2. Previous study [9] showed that electron withdrawing group tend decrease the orbitals energy, but increase the gap. This effect is due to the effect of the electron density shift on the stability of the orbital is bigger on the occupied orbital than the virtual orbitals, thus decrease the orbital energy, but increase the gap between the orbitals.

This effect however is not a linear effect because the strength of a group in shifting electron density is not the only factor. This violation of the electron density band gap relation is exhibited by $\mathrm{HgP}-\mathrm{CHO}$ and $\mathrm{HgP}-\mathrm{CH}_{3}$.

Density of states (DOS): Density of states is the measure of numbers of allowed states per unit volume in any given energy level.In semiconductor science, the density of states is the measure of the probability density of an electron recombine with hole after being excited from an occupied orbital to the virtual orbital. Higher DOS abundance near and below Fermi

\begin{tabular}{cccc}
\multicolumn{4}{c}{ TABLE-2 } \\
\multicolumn{4}{c}{$\begin{array}{c}\text { FRONTIERS ORBITALS AND BAND } \\
\text { GAP ENERGY OF HgP-R [Ref. 9] }\end{array}$} \\
\hline $\mathrm{R}$ & $\mathrm{E}_{\text {LUMO }}(\mathrm{eV})$ & $\mathrm{E}_{\text {Hомо }}(\mathrm{eV})$ & $\mathrm{E}_{\mathrm{g}}(\mathrm{eV})$ \\
\hline $\mathrm{CH}_{3}$ & -2.32 & -4.87 & 2.55 \\
$\mathrm{CHO}$ & -4.01 & -6.47 & 2.46 \\
$\mathrm{COOH}$ & -3.43 & -6.13 & 2.70 \\
$\mathrm{~F}$ & -3.14 & -5.76 & 2.62 \\
$\mathrm{H}$ & -2.49 & -5.34 & 2.85 \\
$\mathrm{I}$ & -3.14 & -5.67 & 2.54 \\
$\mathrm{NH}_{2}$ & -1.67 & -3.46 & 1.79 \\
$\mathrm{NO}_{2}$ & -4.53 & -7.13 & 2.60 \\
$\mathrm{OH}$ & -2.51 & -4.67 & 2.16 \\
$\mathrm{C}_{6} \mathrm{H}_{5}$ & -2.47 & -5.01 & 2.53 \\
\hline
\end{tabular}

level energy mean that the probability of electron-hole recombination is high.

Table-3 showed DOS abundance of virtual orbital is relatively independent of the substituent group, while the DOS abundance of the occupied orbital is significantly affected by the different substituent group. Complexes with electron donating group tend to have lower abundance on occupied orbital because the group shift the electron density toward the porphyrin ring and centre of the complexes, occupying the allowed stated, thus decrease the number of available state in any given energy level and decrease the DOS abundance. The same thing is also causing DOS abundance of virtual orbital not affected by the substituent group on the complexes because virtual orbital is unoccupied by the electron, therefore, the number of available state are independent of the substituent group.

TABLE-3

DENSITY OF STATES OF THE FRONTIER ORBITALS OF HgP-R

\begin{tabular}{ccc}
\hline \multirow{2}{*}{$\mathrm{R}$} & \multicolumn{2}{c}{ DOS abundances $\left(\right.$ states $\left.\mathrm{eV}^{-1} \mathrm{~nm}^{-1}\right)$} \\
\cline { 2 - 3 } & $\mathrm{HOMO}$ & $\mathrm{LUMO}$ \\
\hline $\mathrm{CH}_{3}$ & 0.99970 & 1.99343 \\
$\mathrm{CHO}$ & 1.20392 & 1.99714 \\
$\mathrm{COOH}$ & 1.46417 & 1.99833 \\
$\mathrm{~F}$ & 0.99997 & 1.99945 \\
$\mathrm{H}$ & 1.18704 & 1.99232 \\
$\mathrm{I}$ & 0.82106 & 1.99861 \\
$\mathrm{NH}_{2}$ & 0.99602 & 1.99672 \\
$\mathrm{NO}_{2}$ & 1.57133 & 1.99816 \\
$\mathrm{OH}$ & 0.99786 & 1.75786 \\
$\mathrm{CH}_{6} \mathrm{H}_{5}$ & 1.00059 & 1.99658 \\
\hline
\end{tabular}




\section{Conclusions}

We have used DFT/B3LYP/LanL2DZ calculation to investigate the effect of different substituent groups on the electronic and molecular structure of HgP-R. The calculation result showed that the core molecular structure of the complexes are independent of substituent group due to the steric effect of the $\mathrm{Hg}$ (II) ion.

The electronic structure of the occupied orbitals on the other hand is significantly affected by the different substituent group because of its dependency on the electron density. Complexes with electron withdrawing group will have lower orbital energy due to the orbital stabilization, but higher band gap energy because of the stabilization affect the occupied orbital more than the virtual orbital. Density of states abundance exhibit similar characteristic where the DOS abundance of virtual orbital is not affected by the substituent group while the occupied orbitals DOS abundance will decrease on complexes with electron donating group due to the high electron density on the centre of the molecule.

\section{ACKNOWLEDGEMENTS}

The authors are grateful to Austrian-Indonesian Center for Computational Chemistry for computer time and facilities.

\section{REFERENCES}

1. A.O. Adeyemo and M. Krishnamurthy, Inorg. Chim. Acta, 83, L41 (1984); https://doi.org/10.1016/S0020-1693(00)82504-9.

2. O. Horvath, Z. Valicsek, G. Harrach, G. Lendvay and M.A. Fodor, Coord. Chem. Rev., 256, 1531 (2012); https://doi.org/10.1016/j.ccr.2012.02.011.

3. C.O. Paul-Roth, S. Drouet, A. Merhi, J.A.G. Williams, L.F. Gildea, C. Pearson and M.C. Petty, Tetrahedron, 69, 9625 (2013); https://doi.org/10.1016/j.tet.2013.09.034

4. E. Kuznetsov, Chem. Phys., 469-470, 38 (2016); https://doi.org/10.1016/i.chemphys.2016.02.010.
5. S. Shalabi, M.A. Assem, K.A. Soliman, A.M. El Mahdy and H.O. Taha, Mater. Sci. Semicond. Process., 26, 119 (2014); https://doi.org/10.1016/j.mssp.2014.04.001.

6. P. Ekanayake, M.R.R. Kooh, N.T.R.N. Kumara, A. Lim, M.I. Petra, N.Y. Voo and C.M. Lim, Chem. Phys. Lett., 585, 121 (2013); https://doi.org/10.1016/i.cplett.2013.08.094.

7. J. Wang, W. Zhang and S. Wu, J. Chem. Soc. Pak., 30, 256 (2008).

8. J. Barbee and A.E. Kuznetsov, Comput. Theor. Chem., 981, 73 (2012); https://doi.org/10.1016/j.comptc.2011.11.049.

9. F. Mulya, G.A. Santoso, H.A. Aziz and H.D. Pranowo, AIP Conf. Proc., 1755, 080006 (2016); https://doi.org/10.1063/1.4958514.

10. M.J. Frisch, G.W. Trucks, H.B. Schlegel, G.E. Scuseria, M.A. Robb, J.R. Cheeseman, G. Scalmani, V. Barone, G.A. Petersson, H. Nakatsuji, X. Li, M. Caricato, A. Marenich, J. Bloino, B.G. Janesko, R. Gomperts, B. Mennucci, H.P. Hratchian, J.V. Ortiz, A.F. Izmaylov, J.L. Sonnenberg, D. Williams-Young, F. Ding, F. Lipparini, F. Egidi, J. Goings, B. Peng, A. Petrone, T. Henderson, D. Ranasinghe, V.G. Zakrzewski, J. Gao, N. Rega, G. Zheng, W. Liang, M. Hada, M. Ehara, K. Toyota, R. Fukuda, J. Hasegawa, M. Ishida, T. Nakajima, Y. Honda, O. Kitao, H. Nakai, T. Vreven, K. Throssell, J.A. Montgomery Jr., J.E. Peralta, F. Ogliaro, M. Bearpark, J.J. Heyd, E. Brothers, K.N. Kudin, V.N. Staroverov, T. Keith, R. Kobayashi, J. Normand, K. Raghavachari, A. Rendell, J.C. Burant, S.S. Iyengar, J. Tomasi, M. Cossi, J.M. Millam, M. Klene, C. Adamo, R. Cammi, J.W. Ochterski, R.L. Martin, K. Morokuma, O. Farkas, J.B. Foresman and D.J. Fox, Gaussian 09, Revision 2A, Gaussian, Inc., Wallingford CT (2016)

11. N.M. O'boyle, A.L. Tenderholt and K.M. Langner, J. Comput. Chem., 29, 839 (2008); https://doi.org/10.1002/jcc.20823.

12. P. Hohenberg and W. Kohn, Phys. Rev., 136(3B), B864 (1964); https://doi.org/10.1103/PhysRev.136.B864.

13. W. Kohn and L.J. Sham, Phys. Rev., 72, 650 (1965).

14. A.D. Becke, Phys. Rev. A, 38, 3098 (1988); https://doi.org/10.1103/PhysRevA.38.3098.

15. W. Lee, W. Yang and R.G. Parr, Phys. Rev. B, 37, 785 (1988); https://doi.org/10.1103/PhysRevB.37.785.

16. M.C. Wang, L.S. Sue, B.C. Liau, B.T. Ko, S. Elango and J.-H. Chen, Inorg. Chem., 40, 6064 (2001); https://doi.org/10.1021/ic010275v. 